\title{
Seroconversión de diarrea viral bovina y neosporosis y su implicancia productiva y reproductiva en vacas en la EEA El Mantaro-UNCP, región Junín, Perú
}

\section{Seroconversion of bovine viral diarrhea and neosporosis and productive and reproductive implications in cows in the EEA El Mantaro-UNCP, Junín region, Perú}

\author{
'Arauco Villar, Fernando; Mayorga Sánchez, Noemí \\ Facultad de Zootecnia, Universidad Nacional del Centro del Perú \\ Email: farauco@uncp.edu.pe
}

\begin{abstract}
Resumen
Se determinó la dinámica de la seroconversión de las diarreas viral bovina (DVB) y neosporosis en 111 animales del establo de la EEA El Mantaro-UNCP, región Junín evaluando paralelamente la presentación de animales persistentemente infectados (PI) y la implicancia de la presencia de DVB sobre la producción láctea. Se realizaron tres monitoreos en un año, mediante la prueba de ELISA. El promedio de la prevalencia de DVB fue 73.5 $\%$, la dinámica de su seroconversión fue creciente en el tiempo, y la prevalencia de animales PI fue de $5.4 \%$, correspondiendo un 50\% a animales menores de un año. El promedio de la prevalencia de neosporosis fue 11.8 $\%$ y la dinámica de la seroconversión fue creciente en el tiempo, con tendencia a subir sostenidamente, aunque con valores moderados. La edad y el mayor $\mathrm{N}^{\circ}$ servicios/preñez fue significativamente mayor para DVB que para neosporosis; los casos de vacas repetidoras y abortos estuvieron más asociados con DVB que con neosporosis, existe una baja correlación entre la presentación de casos de DVB y neosporosis, las causas de saca por problemas reproductivos fueron más determinantes (61 $\%$, que las causas por problemas productivos y de conformación, no existiendo asociación entre la producción de leche por campaña de la vacas y los casos positivos de DVB en el hato.
\end{abstract}

Palabras clave: seroprevalencia, seroconversión, diarrea viral bovina, neosporosis, ELISA.

\begin{abstract}
The dynamics of viral diarrhea seroconversion bovine (DVB) and neosporosis was determined in 111 animals from the stable of EEA El Mantaro-UNCP, Junín region as well as evaluating the presentation of persistently infected animals (PI) and the implication of the presence of DVB on milk production. Three surveys were carried out in a year, by means of the ELISA test. The prevalence of DVB average was $73.5 \%$, the dynamics of their sero-conversion was growing at the time, and the prevalence of animals PI was 5.4 per cent, with a $50 \%$ animals younger than one year. The average prevalence of neosporosis was $11.8 \%$ and seroconversion dynamics grew with time, tending to steady climbing, although with moderate values. The age and the greatest services/pregnancy number was significantly greater for DVB than for neosporosis; cows repeaters cases and abortions were more associated with DVB which with neosporosis, there exists a low correlation between the presentation of cases of DVB and neosporosis, sack causes due to reproductive problems were most decisive $(61 \%)$, than the causes by production and conformation problems, with no association between milk production by cows campaign and the positive cases of DVB in the herd.
\end{abstract}

Keywords: seroprevalence, seroconversion, viral bovine diarrhea, neosporosis, ELISA. 


\section{Introducción}

Una de las más importantes causas de la baja productividad ganadera lechera es la presentación de problemas reproductivos, prevaleciendo las enfermedades abortígenas como la neosporosis y la Diarrea Viral Bovina (DVB), que solas o asociadas, afectan la economía del productor al desencadenar problemas como abortos, reabsorciones embrionarias o fetales, mortinatos y el nacimiento de animales débiles, algunos de ellos persistentemente infectados (PI) o portadores del virus de DVB (Houe, 1999). La presencia de estas enfermedades también se refleja en una baja productividad en el hato, aunque en muchas ocasiones estos eventos suelen pasar desapercibidos por no manifestarse tan evidentemente, y por ende el productor no se preocupa por adoptar medidas de control adecuadas. Esta situación se mantiene indefinidamente en las explotaciones por tratarse de enfermedades no denunciables, debido al desconocimiento de su patogenia y epidemiología y falta de un diagnóstico preciso, lo que agrava su impacto sobre los parámetros productivo-reproductivos de las vacas.

Debido a la multicausalidad del aborto bovino, en la mayoría de los casos no es posible realizar un diagnóstico preciso, aunque se asume que entre sus causas tenemos las de tipo infeccioso (virus IBR y DVB, bacterianas como brucelosis bovina y campylobacteriosis, algunos hongos), y por causas parasitarias (tricomoniasis y neosporosis) (Fredes, 2000). Aunque el problema general que afecta la eficiencia reproductiva en los hatos bovinos lecheros tiene como uno de sus eventos responsables al aborto, la multicausalidad y los eventos multifactoriales que intervienen complican el diagnóstico preciso y por ende, la toma de decisiones correctas para revertir esta situación. Es por ello, que todo esfuerzo para reconocer la importancia y el nivel de participación de estos múltiples agentes, contribuirá a la mejora de la eficiencia reproductiva en los hatos. En el hato lechero de la EEA El Mantaro-UNCP, es necesario conocer la dinámica de la seroconversión de ambas enfermedades con la detección de anticuerpos post infección aguda para estas enfermedades, durante un periodo de tiempo determinado, para poder entender como repercuten estos cambios sobre los parámetros productivo-reproductivos de las vacas en lactancia, y poder estimar así, el rol de estas patologías y sus potenciales medidas de corrección, lo cual podría tomarse como modelo de control de estas enfermedades para otros hatos de similares características.

Por tanto, el objetivo general trazado para el presente trabajo fue determinar las variaciones de seroconversión frente a DVB y neosporosis y las variaciones de los parámetros productivo-reproductivos en las vacas de la EEA El Mantaro-UNCP durante el periodo de un año.

La ganadería lechera en la región Junín está en auge y estas enfermedades estarían afectando negativamente la eficien- cia reproductiva de los hatos lecheros. La mayoría de las investigaciones sobre DVB y neosporosis en esta zona se han focalizado en las provincias que conforman el valle del Mantaro, no abarcando otros ámbitos geográficos.

El presente estudio, tuvo como objetivo determinar el estado actual y conocer el estado de la seroprevalencia de DVB y neosporosis de vacas lecheras en la región Junín.

\section{Materiales y métodos \\ Lugar y fecha de ejecución}

El establo de la EEA El Mantaro-UNCP, está ubicado en el valle del Mantaro, provincia de Jauja, región Junín, situado en los andes centrales del Perú, a una altura media de 3200 msnm; geográficamente se encuentra a una longitud sur de $11^{\circ} 55^{\prime}$ y longitud oeste de $75^{\circ}$ $18^{\prime}$. El periodo de realización del trabajo fue entre junio del 2015 a setiembre 2016. Los análisis de laboratorio se realizaron en el Laboratorio de Microbiología de la Facultad de Zootecnia de la UNCP.

\section{Población y muestra}

Se tomaron muestras a la totalidad de vacas (en producción y seca), vaquillas y terneras existentes en el hato de la EEA El Mantaro-UNCP; así como, la información consignada en los registros productivos individuales y mensuales, y la información de los indicadores reproductivos. Como en este caso se va a trabajar con toda la población existente del hato (conjunto formado por todos los elementos a estudiar), se denominó conjunto completo.

\section{Procedimiento}

Las muestras de sangre se obtuvieron por punción directa de la arteria coccígea media, utilizando tubos vacutainers estériles sin anticoagulante, de donde se obtuvieron los sueros, los cuales fueron depositados en viales de 2 $\mathrm{ml}$ debidamente identificados y conservados en congelación a $-20^{\circ} \mathrm{C}$ hasta su procesamiento.

Las muestras fueron procesadas en el Laboratorio de Microbiología de la Facultad de Zootecnia de la UNCP, para detectar anticuerpos contra VDVB usando los kits para detectar anticuerpos específicos contra VDVB (ELISA de bloqueo utilizando el kit IDEXX BVDV Total $\mathrm{Ab}$ ), para detectar el antígeno VDVB (ELISA de captura con el kit Idexx BVDV PI X2 Test), y asimismo, para detectar anticuerpos específicos contra Neospora caninum (ELISA competitivo con el kit N. caninum Antibody Test - VMRD). Los análisis de laboratorio para diagnosticar ambas enfermedades se realizaron en tres momentos: agosto 2015, enero 2016 y agosto 2016).

\section{Prevalencia (P)}

Para determinar la prevalencia de ambas enfermedades se aplicó la siguiente formula:

Prevalencia $(\%)=\mathrm{N}^{\circ}$ muestras positivas $\mathrm{x} 100 /$ total de muestras 
Se utilizó el paquete estadístico SPSS vs 21 para determinar las frecuencias de las variables, gráficos de asociación de variables y tablas de contingencia con chi-cuadrado para el contraste de independencia.

\section{Resultados y discusión}

Del total de vacas evaluadas (80), el 76,25 \% tenían de 1-2 partos, y un $13,75 \%$ tenían entre $3-5$ partos. Al tiempo de la evaluación existían $8,75 \%$ de vaquillas preñadas. El 57,5 \% de los animales evaluados presentó un nivel de problema reproductivo (3-4 repeticiones y más de 5 repeticiones de servicios).

El 8,75\% de los animales evaluados tuvieron antecedentes de aborto, frente a un 91,25\% que no lo reportaron. El aborto reportado se refiere a los casos evidenciables con presencia de fetos abortados, mas no así a los abortos precoces y aquellos en los que no se pudo encontrar fetos en la inspección. Se ha determinado, para los tres periodos donde se realizaron los análisis de laboratorio para detectar DVB en los animales, valores de prevalencia crecientes en el tiempo, siendo en promedio de 73.5 $\%$. En un trabajo realizado en todo el ámbito del valle del Mantaro, Arauco (2015), reportó un valor promedio de $64.71 \%$, siendo para la provincia de Jauja una prevalencia de $70.49 \%$, mientras que Contreras et al. (2000), encontraron $72.4 \%$ de prevalencia y Stahl et al. (2002), detectaron un $73 \%$.

Durante el periodo de la investigación, se ha observado una tendencia creciente a aumentar los valores de prevalencia en el hato, aunque esta tendencia fue menor en el último tercio, debido probablemente a la eliminación (saca) de ganado en un número de 19 animales en un lapso de 12 meses, por diversas causas, principalmente problemas reproductivos, y porque de todos los animales de saca, solo uno de ellos fue negativo a DVB. Al evaluar el status de la presentación de casos altamente positivos $(++)$ y positivos $(+)$ en el hato, durante los dos primeros muestreos ha habido un mayor número de casos positivo $(+)$, que los positivo $(++)$ que se mantuvo con valores iguales; pero en el tercer muestreo, cuando ya se había producido la saca de las vacas, se redujo el número de casos positivo $(+)$ y aumentó el de los casos positivo $(++)$ incluso por encima del valor de los primeros. También se redujo el número de animales negativos proporcionalmente al número de animales que quedó luego de la saca.

La prevalencia real de animales PI / hato es $5.4 \%$. Arauco (2015), encontró una prevalencia de animales persistentemente infectados (PI) con DVB para las cuatro provincias del valle del Mantaro de $5.8 \%$; Jayashi et al. (2005), determinó una prevalencia de 2.7 \% y Huamán et al. (2007), en Majes, Arequipa, encontró 4.0 \% de animales PI. El valor encontrado es indicativo de que existe una presencia de la enfermedad de manera enzoótica en el hato de la EEA El Mantaro - UNCP, lo cual es coincidente con lo reportado por varios autores de que estos animales PI se detectan mayormente en los hatos con prevalencias altas de la enfermedad (Houe, 1993); Arauco (2015), encontró valores de prevalencia para el valle del Mantaro de 15.29 $\%$ registrando Jauja un valor de $10.66 \%$.

Estos resultados son similares a lo reportado por el SENASA (2010), que para la región Junín, registra una prevalencia muestral de 15.79\%; en la SAIS Pachacútec, Junín se reportó una prevalencia de $12.8 \%$ (Puray,2006). Durante el periodo de la investigación, se ha observado una tendencia creciente a aumentar los valores de prevalencia de neosporosis en el hato, y la saca de animales efectuada en el último tercio no ha alterado esta tendencia creciente de la prevalencia.

Se ha encontrado una correlación alta entre la edad y la presentación de DVB, lo cual puede atribuirse a una mayor posibilidad y oportunidad de exposición conforme avanza la edad del animal. Al analizar los casos positivos de DVB en el hato, se ha encontrado que las vacas y vaquillas que requieren de 3, 45 y más de 5 servicios/preñez corresponden a 20 animales (27\% de los animales seropositivos).

$\mathrm{Al}$ analizar la presencia de DVB en el hato en general con los casos de aborto detectados durante el periodo de la investigación, se encontró una correlación significativa entre estas variables. Asimismo, se evaluó los casos seropositivos de DVB, 7 de ellos (9,5\%) presentaron aborto, mientras que en el 90,5\% de los casos seropositivos no se reportaron casos de aborto. Al analizar los casos de abortos reportados y la presencia de neosporosis en el hato, se aprecia una correlación positiva baja. En solo dos casos (20 $\%$ ) seropositivos a neosporosis se ha reportado presencia de casos de aborto, mientras que en el $80 \%$ de casos seropositivos no se han reportado abortos.

Al correlacionar los casos de DVB y neosporosis en el hato, encontramos que existe una correlación bastante baja (no significativa) entre ambas enfermedades en el hato $(r=0,072)$.

Se han producido 23 bajas de ganado durante el periodo de evaluación, correspondiendo a un $61 \%$ por causas reproductivas (vacas problema, animales machorras, con intervalo post parto prolongado), un $26 \%$ por causas productivas y mala conformación y por mortalidad $3 \mathrm{ca}-$ sos (2 por timpanismo y un caso de neumonía).

Se ha evaluado el nivel de asociación entre los resultados de la prueba Elisa para detectar anticuerpos de DVB con el nivel productivo (alto o bajo) de las vacas en producción, durante todo el periodo de evaluación, obteniendo a la prueba un nivel de significación 0.897 que es mayor a 0.05 , por lo que podemos aseverar que los niveles de producción de leche de las vacas evaluadas no están asociados con la presencia de DVB en el hato. 


\section{Referencias bibliográficas}

Arana DC, Echevarría C L, Segura CJ. 2006. Factores que afectan el intervalo parto-primer servicio y primer servicio-concepción en vacas lecheras del Valle del Mantaro durante la época lluviosa. Rev Inv Vet Perú v. 17 n.2 Lima.

Arauco VF. 2015. Epidemiología y caracterización de los factores de riesgo de diarrea viral bovina y neosporosis en bovinos del valle del Mantaro - Región Junín. Tesis Doctorado UNMSM. Disponible en: http: / / cybertesis.unmsm. edu.pe/handle/cybertesis/4500

Atocsa J, Chávez A, Casas E, Falcón N. 2005. Seroprevalencia de N. caninum en bovinos lecheros criados al pastoreo en la provincia de Melgar, Puno. Rev Inv Vet Perú, 16(19): 71-75.

Baker J.C. 1995. The clinical manifestations of bovine viral diarrhea infection. Vet Clinics North Am: Food An Pract, $\mathrm{N}^{\circ} 11: 425-445$.

Barling KS, Lunt DK, Snowden KF, Thompson JA. 2001. Association of serologic status for Neospora caninum and postweaning feed efficiency in beef steers. J Am Vet Med Ass, 219: 1259-1262.

Bautista MF, Cisneros NF, Ciprian CA, Martínez AA. 2013. Seroprevalencia de VDVB en cuencas ganaderas de 5 distritos de la Región Ayacucho. [Portal web: BuenasTareas.com]. Disp. en: http://www.buenastareas.com/ensayos/Seroprevalencia-Del-Virus-De-La-Diarrea/32356873.html

Cabello RK, Quispe CR, Rivera GH. 2006. Frecuencia de los virus PI-3,VRSB y DVB en un rebaño mixto de una comunidad campesina de Cusco. Rev Inv Vet Perú, 17(2): 167-172.

Cabrera M, Ortiz P, Claxton J, Williams D, Trees A. 2000. Evidencia serológica de infección por N. caninum en ganado vacuno en Perú. Res. IV Cong. Peruano Parasitología. Lima p. 212.

Cahuana CJ. 2006. Seroprevalencia de Neospora caninum en bovinos lecheros en el sector Sama grande del Distrito de Sama-Inclán -Tacna. Tesis Título Méd Vet y Zoot, Univ. Católica de Santa María-Arequipa, Perú.

Cárdenas AC, Rivera GH, Araínga RM, RamírezVM, De Paz MJ. 2011. Prevalencia del virus de la diarrea viral bovina y de animales portadores del virus en bovinos en la provincia de Espinar, Cusco. Rev. Investig.Vet. Perú, v. 22 n.3 Lima jul./sep.
Contreras NG, Stahl K, Arana DC, Rivera GH. 2000. Anticuerpos contra el virus de la diarrea viral bovina en muestras de leche de bovinos del valle del Mantaro (Jauja, Concepción y Huancayo). Rev Inv Vet Perú, Vol $11 \mathrm{~N}^{\circ}$ 1: 58-65.

Dubey JP. 2003. Review of N. caninum and neosporosis in animals. Kor J Parasitol 41(1): 1-16.

Escurra OJC. 2003. Seroprevalencia de Neosporosis bovina diagnosticada mediante inmunofluorescencia directa, en predios de la campiña de Baños del Inca provincia de Cajamarca- año 2001. Tesis Fac. Cs. Vet. Univ. Nac. de Cajamarca. 95 pp.

Fredes MF. 2000. La neosporosis una parasitosis emergente. TecnoVet, [S.1.], v6, No3. Disp en: http:// www.revistas.uchile.cl/index.php/RT/article/ view/5264/5144.

Givens MD, Marley MS. Immunology of chronic BVDV infections. Biologicals. 2013. 41(1):26-30.

Granados ZS. 2012. Frecuencia de Neospora caninum en bovinos lecheros de 4 distritos del valle del Mantaro. Tesis Fac Med Vet. UNMSM. Lima. 84pp.

Hässig M. y Gottstein B. 2002. Epidemiological investigations of abortions due to Neospora caninum on Swiss dairy farms. Vet Rec, 150: 538-542.

Houe H. 1993. Survivorship of animals persistently infected with bovine virus diarrhoea virus (BVDV). Prev Vet Med, 15:275-283.

Houe H. 1999. Epidemiological features and economical importance of bovine viral diarrhea virus BVDV infection. Vet Microbiol 64: 89-107.

Huamán JC, Rivera H, Araínga M, Gavidia C, Manchego A. 2007. Diarrea viral bovina y animales portadores del virus en hatos productores de leche de la irrigación de Majes, Arequipa. Rev Inv Vet Perú 18: 141-149.

Jayashi C.F., Gavidia C.C., Arainga M.R., Manchego A.S. y Rivera H.G. 2005. Dinámica de seroconversión en hembras bovinas post eliminación de animales portadores del virus de la diarrea viral bovina. Revista de Investigaciones Veterinarias del Perú, v. 16 n.1

Kobrak A. y Wever E.L. 1997. Bovine diarrhea virus: an update. Revista Argentina de Microbiología, N 29: 47-61.

Mamani J. 2007. Seroprevalencia Neospora caninum en bovinos lecheros en Distrito de Moquegua, Provincia Mariscal Nieto y Departamento de Moquegua-2007. Tesis Titulo 
Méd Vet y Zoot. Univ. Católica Sta. María. Arequipa, Perú. pp. 1-85.

Matsuno K, SakodaY, Kameyama K, Tamai K, Ito A, Kida H. 2007. Genetic and pathobiological characterization of BVDV recently isolated from cattle in Japan. J Vet Med Sci. 69:515-20.

Olivera S L. 2001. Sanidad del ganado lechero de la Cuenca del Sur. Rev. Inv. Vet. Perú v.12 n.2 Lima jul./dic.

Orrego J.A., Delgado A., y Echevarría L. 2003. Vida productiva y principales causas de descarte de vacas Holstein en la cuenca de Lima. Rev Inv Vet Perú 2003; 14 (1): 68-73

Palomares-Naveda R.A. 2008. Desarrollo Sostenible de Ganadería Doble Propósito: Diagnóstico de la diarrea viral bovina para la mejora de la eficiencia reproductiva. Manual de ganadería doble propósito. Cap. LIII. Ed: González-Stagnaro C. y Soto E. Disponible en: http: / / www.avpa.ula.ve/libro_desarrollosost/pdf/capitulo_53.pdf

Puray Ch N, Chávez VA, Casas AE, Falcón PN, Casas VG. 2006. Prevalencia de Neospora caninum en bovinos de una empresa ganadera de la sierra central del Perú. Rev Inv Vet Perú, 17 (2): 189-194.

Rivera H. 1993. El virus de la diarrea viral bovina. Rev. Pec. Inv. IVITA (Perú) 6(1): 1-7.

Rivera H. 2001. Etiología infecciosa del aborto bovino. Rev Inv Vet Perú Supl 1: 95-99.

Silva SP, Chávez VA, Rivera GH, Casas E. 2002. Seroprevalencia de $N$. caninum en bovinos lecheros del valle de Lima. Rev Inv Vet Perú, 13(2): 51-55.

Ståhl K, Rivera H, Vagsholm I, Moreno-López J. 2002. Bulk milk testing for antibody seroprevalences to BVDV and BHV-1 in a rural region of Peru. Prev. Vet. Med. 56: 193-202.

Ståhl K. 2006. Virus de la diarrea viral bovina y otros patógenos reproductivos: estudios epidemiológicos en el ganado vacuno del Perú. Acta Universitatis Agriculturae Sueciae, 53:1652-6880.

Torres L. 2006. Seroprevalencia de Neospora caninum en ganado vacuno lechero de Chota. Tesis de Médico Veterinario. Fac Cs Vet, Univ. Nac. de Cajamarca. 81 p. 